\title{
BMJ Open Does angiography increase the risk of impairment in renal function during non-operative management of patients with blunt splenic injuries? A cross- sectional study in southern Taiwan
}

\author{
Ting-Min Hsieh, ${ }^{1}$ Tzu-Hsien Tsai, ${ }^{2}$ Chih-Che Lin, ${ }^{3}$ Ching-Hua Hsieh ${ }^{1}$
}

To cite: Hsieh T-M, Tsai T-H, Lin C-C, et al. Does angiography increase the risk of impairment in renal function during non-operative management of patients with blunt splenic injuries? A cross-sectional study in southern Taiwan. BMJ Open 2016;6:e012205.

doi:10.1136/bmjopen-2016012205

- Prepublication history for this paper is available online. To view these files please visit the journal online (http://dx.doi.org/10.1136/ bmjopen-2016-012205).

$\mathrm{C}-\mathrm{CL}$ and $\mathrm{C}-\mathrm{HH}$ contributed equally.

Received 8 April 2016

Revised 27 September 2016

Accepted 29 September 2016

CrossMark

For numbered affiliations see end of article.

Correspondence to Dr Ching-Hua Hsieh; m93chinghua@gmail.com

\section{ABSTRACT}

Objectives: The aim of the present study was to assess whether angiography after contrast-enhanced CT (CECT) as per the policy of non-operative management would add to the risk of acute kidney injury in patients with blunt splenic injuries (BSIs).

Design: Cross-sectional study.

Setting: Taiwan.

Participants: Patients with BSI aged $>16$ years, admitted to a level I trauma centre during the period of January 2004 to December 2014, were retrospectively reviewed. A total of 326 patients with BSI with CECT were included in the study, of whom 100 underwent subsequent angiography and 226 did not.

Main outcome measures: Incidence of contrastinduced nephropathy (CIN) and renal function as measured by the 48-hour serum creatinine (SCr) levels. Results: No significant difference between the patients who underwent angiography and those who did not in terms of the initial haemoglobin $(\mathrm{Hb}), \mathrm{SCr}$ or estimated glomerular filtration rate (eGFR) level on arrival at the emergency department, 48 hours later, or at discharge. No significant difference in the incidence of CIN was found between these two groups of patients regardless of the criteria for identifying CIN. In the group of patients aged $\geq 55$ years, those who underwent angiography had a significantly worse 48-hour SCr level than those who did not undergo the treatment. In addition, there was no significant difference in the 48hour SCr level between the two groups of patients when subgrouping the patients according to sex, large haemoperitoneum revealed on CT, systolic blood pressure, initial $\mathrm{Hb}$, initial $\mathrm{SCr}$ and initial eGFR levels.

Conclusions: This study demonstrated that angiography does not increase the incidence of CIN, and was not a risk factor to renal function impairment in patients with BSI who had undergone CECT.

\section{BACKGROUND}

With the advances in radiological diagnostics and therapeutic procedures, including contrast-enhanced $\quad$ CT $\quad(\text { CECT })^{1}$ and

\section{Strengths and limitations of this study}

- This retrospective study had its inherent bias; however, the patients with blunt splenic injury were treated with adherence to protocol-based strategy, including with non-operative management policy so as to mitigate the retrospective bias as much as possible.

- Serum creatinine as the main measurement of outcome reflects a less accurate renal function than creatinine clearance and may lead to a bias.

- A lack of detailed data on administrated fluid volume, contrast dosage and long-term renal function may cause some bias in the outcome measurement.

angiographic intervention ${ }^{2-4}$ non-operative management (NOM) has become common at the emergency department (ED) for early diagnosis and management of visceral injury. However, the issue of potential contrastinduced nephropathy (CIN) has raised serious concerns. ${ }^{3} 5$ CIN is commonly defined as an increase in serum creatinine (SCr) of $0.5 \mathrm{mg} / \mathrm{dL}$ or a $25 \%$ increase from the baseline value assessed at 48 hours following contrast administration. ${ }^{6}$ Some authors suggest that the association of renal function impairment with the contrast medium may be overemphasised, ${ }^{7-11}$ as reported that the intravenous contrast did not cause an increased risk of acute kidney injury even in patients with comorbidities predisposing them to nephrotoxicity. ${ }^{12-14}$ In addition, a significant subset of patients with $<50 \%$ left of functional nephrons did not exhibit, or only have marginal, clinical changes in SCr. ${ }^{15}$ There are still some concerns, however, regarding patients with trauma who are usually hypovolaemic and cannot undergo detailed assessment of renal function 
and often have to undergo more than one contrastenhanced imaging study. Currently, the reported incidence of CIN is widely varied (ie, 1.9-24\%) in studies where patients with trauma are concerned. ${ }^{3}$ 8-10 16-19 With the growing popularity of NOM for patients with blunt splenic injury (BSI) ${ }^{2}{ }^{4}$ serial infusions of contrast within a short period are needed but the issue of whether extensive contrast medium causes a detrimental impact on renal function in this patient population is less discussed. Therefore, the aim of this study is to assess whether angiography after CECT under the policy of NOM would add to the risk of renal injury in patients with BSI.

\section{METHODS}

Study population

The data were extracted and retrospectively reviewed from the institutional trauma registry with medical records of all patients with BSI admitted to a level I trauma centre (Kaohsiung Chang Gung Memorial Hospital) from January 2004 to December 2014. Patients with trauma who underwent CECT of the abdomen under the diagnosis of BSI were managed according to our management algorithm for $\mathrm{BSI}^{4}$ where patients would initially undergo NOM. The indications for angioembolisation included grade $4 / 5$ splenic injury, contrast extravasation or significant haemoperitoneum as seen on CT. If haemodynamics was unstable or peritonitis was suspected, NOM was converted to a laparotomy. A NOM failure was defined as a patient who returned to the operation room subsequently after conservative treatment. The patients receiving either NOM or laparotomy were observed in the intensive care unit (ICU), where laboratory data were acquired daily. All patients who underwent initial diagnostic intravenous abdominal CECT with or without angiography for splenic angioembolisation were included in this study, while patients with a known history of end-stage renal disease, age $<16$ years, incomplete data, initial CECT performed at another facility, angioembolisation not performed within 48 hours after CECT, and those who expired within 48 hours were excluded. The dose of intravenous contrast medium Iohexol (OMNIPAQUE) for abdominal CECT and intra-arterial angiography was $60-120 \mathrm{cc}$ and $100-150 \mathrm{cc}$, respectively, depending on the weight of the patient in accordance with the protocol of the radiological department. The upper limit of overall contrast dose was $1.5 \mathrm{~mL} / \mathrm{kg}$ for abdominal CECT and $3 \mathrm{~mL} / \mathrm{kg}$ for angiography. Other than fluid resuscitation, no prophylactic measures against CIN were used routinely. An informed consent was waived according to the regulation of Institutional Review Board (IRB).

\section{Collection of injury severity and measurement data}

The Injury Severity Score (ISS) and Splenic Injury Scale (SIS) were calculated according to the American Association for the Surgery of Trauma grading of injury. ${ }^{20}$ The estimated glomerular filtration rate (eGFR) was calculated using the Modification of Diet in Renal Disease (MDRD) study equation. ${ }^{21}$ Significant haemoperitoneum on CT was defined as the presentation of fluid accumulation over the perisplenic, paracolic and pelvic regions. ${ }^{4}$ CIN was defined at 48 hours after contrast administration using the Barrett and Parfery criteria, ${ }^{6}{ }^{22}$ Acute Kidney Injury Network (AKIN) ${ }^{23}$ or Risk of renal dysfunction, Injury to the kidney, Failure of kidney function, Loss of kidney function and End-stage renal disease classification (RIFLE) ${ }^{24}$ Kidney trauma was defined as direct trauma to the kidney noted using CT.

Data obtained included demographics, body mass index (BMI), comorbidities including diabetes, hypertension, liver cirrhosis, history of habitual smoking and alcohol consumption, mechanism of injury, ISS, SIS, initial vital signs including systolic blood pressure (SBP) and heart rate on arrival at the $\mathrm{ED}$, haemoglobin $(\mathrm{Hb})$ level on arrival at the ED and 24 hours later at the ICU, renal function data acquired throughout the course of hospitalisation including initial SCr level with eGFR at ED on initial arrival, repeated SCr level with eGFR 48 hours later and a follow-up of the SCr level with eGFR at discharge, blood transfusion units at ED and during hospitalisation, length of stay in ICU and hospital, CT presentation including contrast blush, significant haemoperitoneum and kidney trauma, and outcomes including the incidence of CIN and mortality.

\section{Analysis of the grouped participants}

The clinical presentation and outcomes were compared between patients with and without angiography. To evaluate the possible association between the risk factor and CIN, all patients were further divided into subgroups according to different clinical conditions or comorbidities for comparison between patients with and without angiography. These factors include comorbidities (diabetes, hypertension, cirrhosis), old age ( $\geq 55$ years), ${ }^{3} 1617$ sex, obesity (BMI $\left.\geq 30\right),{ }^{25}$ habitual smoking or alcohol consumption, pre-existing renal insufficiency (initial $\mathrm{SCr}>1.5 \mathrm{mg} / \mathrm{dL}$ or initial eGFR $<60 \mathrm{~mL} /$ min), ${ }^{8} 1018$ shock on arrival $(\mathrm{SBP}<90 \mathrm{~mm} \mathrm{Hg}),{ }^{8} 101417$ anaemia with massive bleeding (initial $\mathrm{Hb}<11 \mathrm{~g} / \mathrm{dL}$ ), ${ }^{26}$ need for transfusion (24-hour $\mathrm{Hb}<10 \mathrm{~g} / \mathrm{dL}$ ), ${ }^{27}$ significant haemoperitoneum on $\mathrm{CT}^{4}$ severe injury (ISS $\geq 16$, SIS 4,5$){ }^{4,} 10,20,27$ The Hb level of $11 \mathrm{~g} / \mathrm{dL}$ or 24 -hour $\mathrm{Hb}$ of $10 \mathrm{~g} / \mathrm{dL}$ was adopted in this study according to reported evidence that these have been deemed as a cut-off point for initiating the massive blood transfusion protocol, and guiding the need for blood transfusions to prevent trauma-induced coagulopathy, respectively. ${ }^{26} 27$ The occurrence of CIN was used as the primary measurement of outcome, whereas the change of 48-hour SCr against those initial SCr on arrival at ED, the blood transfusion units, the length of stay in ED or hospital, ${ }^{25}$ and the mortality were used as the secondary measurement of outcome. 


\section{Statistical analysis}

Interval data were reported as mean \pm SD. The Mann-Whitney $U$ test and Wilcoxon rank-sum test were used to analyse continuous variables that were not normally distributed to compute for differences between the groups. Categorical data were analysed by Fisher's exact test and $\chi^{2}$ test. Two comparable populations of patients with and without angiography were created by the 1:1 Greedy method using NCSS software (NCSS V.10; NCSS Statistical software, Kaysville, Utah) according to the propensity-matched scores, which were calculated using a logistic regression model with age, gender, ISS, SIS and 24-hour $\mathrm{Hb}$ as covariates for adjustment. Comparison between these two propensity scorematching populations regarding the 0 -hour and 48-hour SCr levels was performed. Significance was set at $\mathrm{p}<0.05$.

\section{RESULTS}

\section{Patient characteristics}

A total of 405 patients with BSI were enrolled at our hospital during the 11-year period of the study (figure 1). After the exclusion of 79 patients, 326 patients were included in the study, of whom 100 had undergone angiography and 226 had not. Among the 100 patients who had undergone angiography, 86 received initial angiography, and 14 received an angiography after the failure of clinical observation. Among the 226 patients who did not have angiography, 150 received only clinical observation, 63 had initial laparotomy due to unstable haemodynamics or suspicion of peritonitis, and 13 had the conversion to laparotomy because of failure in clinical observation (NOM failure). The mean age of the studied population was $36.3 \pm 17.3$ years, and majority were men $(n=236,72.4 \%$; table 1$)$. No significant difference was seen between the patients with and without angiography in regard to the BMI, comorbidities (hypertension, liver cirrhosis and diabetes mellitus) and personal history (smoking, alcohol consumption). The injury severity (SIS and ISS) and the presented initial vital signs were similar between these two groups of patients, except that there were less patients categorised as SIS I who had undergone angiography. CT examination revealed that there was a higher incidence of contrast blush and large haemoperitoneum but a lower incidence of kidney trauma in patients who underwent angiography than in those who did not.

\section{Renal function and outcome during the hospitalisation}

No significant difference was found between the two study groups in terms of the initial $\mathrm{Hb}, \mathrm{SCr}$ or eGFR level on arrival at ED, 48 hours later or at discharge (table 2). However, at 24 hours, the $\mathrm{Hb}$ level of those who underwent angiography was significantly lower than that of those who had not undergone angiography (10.1 \pm 1.6 vs $10.8 \pm 2.3, \mathrm{p}=0.002$ ), which could imply that angiography may be correlated to patients with an observed or expected increase in blood loss. This phenomenon could also be reflected with an increased number of units of blood transfusions at the ED for those who underwent angiography compared with that for those who did not $(2.3 \pm 2.5$ vs $1.6 \pm 3.0, \mathrm{p}<0.001)$. Furthermore, an initial acute renal insufficiency was noted in the total. In either group, the renal function, measured by $\mathrm{SCr}$ and eGFR levels, gradually improved at 48 hours when compared with the measurements taken on arrival at the ED. Likewise, renal function also gradually improved at discharge when compared with the measurement taken 48 hours after arrival.

\section{Incidence of CIN and outcome}

Thirty-six patients, who met at least one of the three criteria and survived for at least 48 hours after abdominal CECT, were investigated. No significant difference in the incidence of CIN was found between these two groups of patients regardless of the criteria for identifying CIN.
Figure 1 Flow chart of the studied patients with BSI. *Definition of CIN according to Barrett and Parfrey criteria; §definition of CIN according to AKIN criteria; †definition of CIN according to RIFLE criteria. AKIN, Acute Kidney Injury Network; BSI, blunt splenic injury; CECT, contrast-enhanced CT; CIN, contrast-induced nephropathy; RIFLE, Risk of renal dysfunction, Injury to the kidney, Failure of kidney function, Loss of kidney function and End-stage renal disease classification.

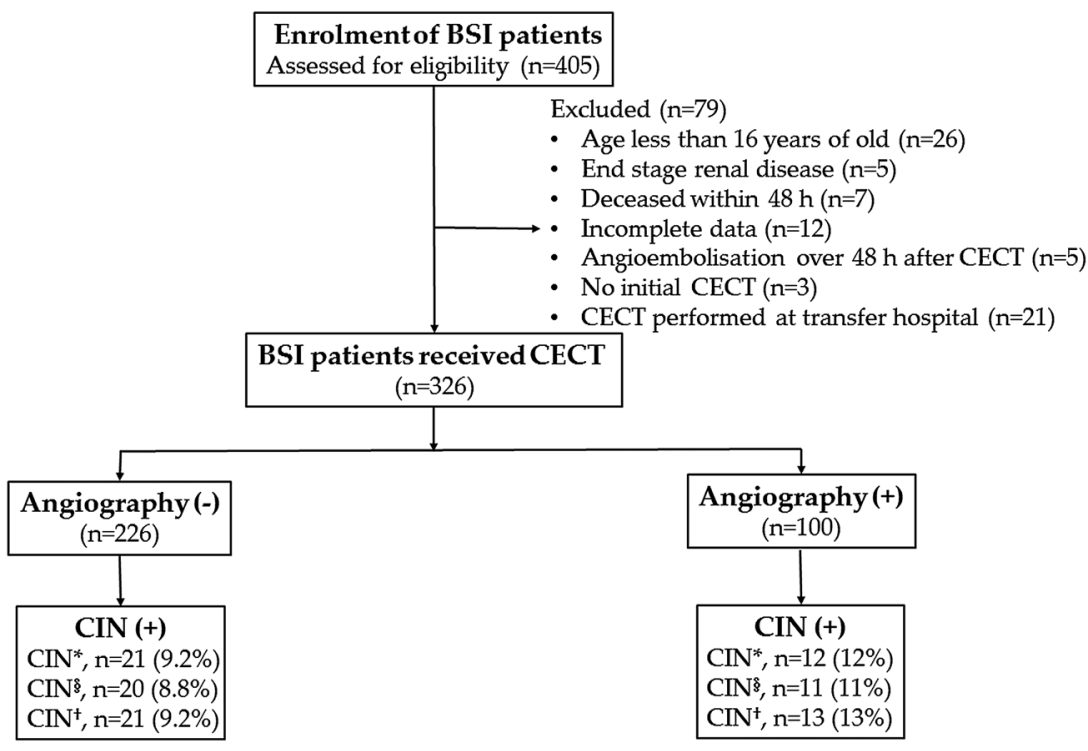


Table 1 Patient characteristics and injury severity of the study population

\begin{tabular}{|c|c|c|c|c|}
\hline & $\begin{array}{l}\text { All patients } \\
n=326\end{array}$ & $\begin{array}{l}\text { Angiography (-) } \\
\mathrm{n}=226\end{array}$ & $\begin{array}{l}\text { Angiography (+) } \\
n=100\end{array}$ & p Value \\
\hline Age (years) & $36.3 \pm 17.3$ & $36.5 \pm 17.7$ & $36.0 \pm 16.5$ & 0.82 \\
\hline Male, n (\%) & $236(72.4)$ & $170(75.2)$ & $66(66.0)$ & 0.09 \\
\hline BMI, mean $\left(\mathrm{kg} / \mathrm{m}^{2}\right)$ & $24.3 \pm 4.4$ & $24.1 \pm 4.2$ & $24.7 \pm 4.8$ & 0.46 \\
\hline \multicolumn{5}{|l|}{ Comorbidities } \\
\hline Hypertension, n (\%) & $32(9.8)$ & $22(9.7)$ & $10(10.0)$ & 0.94 \\
\hline Liver cirrhosis, n (\%) & $30(9.2)$ & $21(9.3)$ & $9(9.0)$ & 0.93 \\
\hline Diabetes mellitus, n (\%) & $16(4.9)$ & $13(5.8)$ & $3(3.0)$ & 0.29 \\
\hline \multicolumn{5}{|l|}{ Personal history } \\
\hline Smoking, n (\%) & $125(38.3)$ & $87(38.5)$ & $38(38.0)$ & 0.93 \\
\hline Alcohol, n (\%) & 109 (33.4) & $77(34.1)$ & 32 (32.0) & 0.71 \\
\hline \multicolumn{5}{|l|}{ Injury severity } \\
\hline \multicolumn{5}{|l|}{ Splenic Injury Scale } \\
\hline I & $36(11.0)$ & $31(13.7)$ & $5(5.0)$ & $<0.001$ \\
\hline II & $84(25.8)$ & $76(33.6)$ & $8(8.0)$ & \\
\hline III & $109(33.4)$ & $56(24.8)$ & $53(53.0)$ & \\
\hline IV & $60(18.4)$ & 39 (17.3) & $21(21.0)$ & \\
\hline V & $87(11.4)$ & $24(10.6)$ & $13(13.0)$ & \\
\hline ISS & $18.6 \pm 10.7$ & $18.13 \pm 10.9$ & $19.7 \pm 10.1$ & 0.23 \\
\hline \multicolumn{5}{|l|}{ Initial vital signs } \\
\hline $\mathrm{SBP}(\mathrm{mm} \mathrm{Hg})$ & $108.6 \pm 25.9$ & $110.2 \pm 26.9$ & $104.8 \pm 23.0$ & 0.07 \\
\hline HR (bpm) & $105.1 \pm 27.5$ & $105.7 \pm 27.4$ & $103.7 \pm 27.9$ & 0.60 \\
\hline \multicolumn{5}{|l|}{ CT presentation } \\
\hline Contrast blush, n (\%) & $94(28.8)$ & $40(17.7)$ & $54(54.0)$ & $<0.001$ \\
\hline Large haemoperitoneum, n (\%) & $106(32.5)$ & $61(27.0)$ & $45(45.0)$ & $<0.001$ \\
\hline Kidney trauma, n (\%) & $58(17.8)$ & $47(20.8)$ & $11(11.0)$ & $<0.001$ \\
\hline
\end{tabular}

Those patients with BSI who had undergone angiography stayed longer in the hospital (18.2 vs 14.0 days, $\mathrm{p}=0.002$ ) and ICU (6.0 vs 4.7 days, $\mathrm{p}=0.002$ ) than those who had not undergone angiography. The overall mortality of the BSI patient population was $6.1 \%$ (20/326) and no significant difference in mortality rate was found between these two groups of patients.

\section{Analysis of the grouped participants}

Comparisons of the initial and 48-hour SCr levels of the grouped participants according to various conditions are summarised in table 3. In the group of patients aged $\geq 55$ years, those who underwent angiography had a significantly worse 48-hour SCr level than those who had not. In contrast, the groups of patients with an ISS $\geq 16$, an SIS of $4 / 5$, and a 24 -hour $\mathrm{Hb}<10 \mathrm{~g} / \mathrm{dL}$ who underwent angiography had a significantly better 48 -hour $\mathrm{SCr}$ level than those who did not. However, the differences in the SCr level may not be large and generally $<0.1$. In addition, there was no significant difference in the 48-hour SCr level between these two groups of patients when they were classified according to sex, large haemoperitoneum revealed on $\mathrm{CT}, \mathrm{SBP}<90 \mathrm{~mm} \mathrm{Hg}$, initial $\mathrm{Hb}<11 \mathrm{~g} / \mathrm{dL}$, initial $\mathrm{SCr}>1.5 \mathrm{mg} / \mathrm{dL}$, initial eGFR $<60 \mathrm{~mL} / \mathrm{min}$ or kidney trauma. In addition, 91 well-balanced pairs of patients were assessed for outcome assessment after propensity score matching of age, gender, ISS, SIS and 24-hour $\mathrm{Hb}$ (table 4). In these propensity score-matched patients, who present no significant difference in co-variables of age, gender, ISS, SIS and 24-hour $\mathrm{Hb}$, patients with angiography present no significant outcomes including 0-hour SCr $(1.1 \pm 0.4$ vs $1.0 \pm 0.3, \mathrm{p}=0.338)$ and 48 -hour $\mathrm{SCr}(0.9 \pm 0.5$ vs $0.9 \pm 0.5$, $\mathrm{p}=0.873$ ) levels than those who had not received angiography.

\section{DISCUSSION}

In this study, a $10 \%$ incidence of CIN was seen under different criteria. However, there was no significant difference regarding the occurrence of CIN in terms of measuring the 48-hour SCr or eGFR between patients undergoing abdominal CECT with and without angiography was $11-13 \%$ and $8.8-9.2 \%$, respectively. The results indicate that a second dose of contrast for angiography does not increase the incidence of CIN or injure the kidney despite prior CECT. In addition, in these propensity score-matched 91 well-balanced patients, who present no significant difference in co-variables of age, gender, ISS, SIS and 24-hour $\mathrm{Hb}$, there was no significant difference in 0-hour and 48-hour SCr levels 
Table 2 Laboratory data and hospitalisation course of the study population

\begin{tabular}{|c|c|c|c|c|}
\hline & $\begin{array}{l}\text { All patients } \\
n=326\end{array}$ & $\begin{array}{l}\text { Angiography (-) } \\
n=226\end{array}$ & $\begin{array}{l}\text { Angiography (+) } \\
n=100\end{array}$ & p Value \\
\hline \multicolumn{5}{|l|}{$\mathrm{Hb}(\mathrm{g} / \mathrm{dL})$} \\
\hline Initial $\mathrm{Hb}$ & $11.9 \pm 2.4$ & $12.0 \pm 2.4$ & $11.7 \pm 2.4$ & 0.12 \\
\hline 24-hour Hb & $11.6 \pm 2.1$ & $10.8 \pm 2.3$ & $10.1 \pm 1.6$ & 0.002 \\
\hline \multicolumn{5}{|l|}{$\mathrm{SCr}(\mathrm{mg} / \mathrm{dL})$} \\
\hline Initial SCr & $1.03 \pm 0.33$ & $1.03 \pm 0.32$ & $1.05 \pm 0.39$ & 0.63 \\
\hline 48-hour SCr & $0.94 \pm 0.47$ & $0.94 \pm 0.42$ & $0.95 \pm 0.58$ & 0.28 \\
\hline Discharge SCr & $0.84 \pm 0.56$ & $0.85 \pm 0.52$ & $0.83 \pm 0.60$ & 0.08 \\
\hline \multicolumn{5}{|l|}{ eGFR $\left(\mathrm{mL} / \mathrm{min} / 1.73 \mathrm{~m}^{2}\right)$} \\
\hline Initial eGFR & $84.8 \pm 28.0$ & $85.2 \pm 27.9$ & $83.7 \pm 28.6$ & 0.84 \\
\hline 48-hour eGFR & $99.9 \pm 36.2$ & $99.0 \pm 35.2$ & $102.1 \pm 38.9$ & 0.28 \\
\hline Discharge eGFR & $113.8 \pm 3.9$ & $111.9 \pm 38.2$ & $118.1 \pm 41.4$ & 0.12 \\
\hline \multicolumn{5}{|l|}{ Blood transfusion (units) } \\
\hline At ED & $1.8 \pm 2.9$ & $1.6 \pm 3.0$ & $2.3 \pm 2.5$ & $<0.001$ \\
\hline During hospitalisation & $4.7 \pm 8.6$ & $4.7 \pm 9.1$ & $4.7 \pm 7.3$ & 0.40 \\
\hline \multicolumn{5}{|l|}{ Outcome } \\
\hline $\mathrm{CIN},{ }^{*} \mathrm{n}(\%)$ & $33(10.1)$ & $21(9.2)$ & $12(12.0)$ & 0.46 \\
\hline $\mathrm{CIN}, \S \mathrm{n}(\%)$ & $31(9.5)$ & $20(8.8)$ & $11(11.0)$ & 0.55 \\
\hline $\mathrm{CIN}, \dagger \mathrm{n}(\%)$ & $34(10.4)$ & $21(9.2)$ & $13(13.0)$ & 0.31 \\
\hline \multicolumn{5}{|l|}{ Course in hospital } \\
\hline Hospital stay (days) & $15.2 \pm 11.2$ & $14.0 \pm 10.0$ & $18.2 \pm 13.2$ & 0.002 \\
\hline ICU stay (days) & $5.1 \pm 5.6$ & $4.7 \pm 5.2$ & $6.0 \pm 6.5$ & 0.002 \\
\hline Mortality, n (\%) & $20(6.1)$ & $15(6.6)$ & $5(5.0)$ & 0.56 \\
\hline $\begin{array}{l}\text { The } p \text { value indicates angio } \\
\text { Data are presented as mea } \\
\text { Angiography (-): patients re } \\
\text { Angiography (+): patients ur } \\
{ }^{*} \mathrm{CIN} \text { : based on Barrett and } \\
\S \mathrm{CIN} \text { : based on AKIN criteri } \\
\text { †CIN: based on RIFLE crite } \\
\text { AKIN, Acute Kidney Injury } \\
\text { rate; Hb, haemoglobin; ICU, } \\
\text { kidney function and End-sta }\end{array}$ & $\begin{array}{l}\text { vs angiography } \\
\text { Imber (\%). } \\
\text { hancement CT a } \\
\text { erial enhanceme } \\
\text { eria. }\end{array}$ & angiography. & $\begin{array}{l}\text { estimated } g \\
\text { of kidney } f\end{array}$ & $\begin{array}{l}\text { ation } \\
\text { of }\end{array}$ \\
\hline
\end{tabular}

between the patients with and without angiography. The results of this study are consistent with the report that intravenous contrast administration is not associated with excess risk of acute kidney injury among patients with comorbidities reported to predispose them to nephrotoxicity. ${ }^{12}$ The results are also supported by some studies in trauma populations that failed to identify contrast dosage as a predisposing factor for CIN. 810131416171925 Accordingly, it appears that the risk of intravenous contrast-induced nephrotoxicity may not really be as great as we have come to believe. ${ }^{11}$

Although some authors have found that there was no association between increasing age ( $>55$ years) and risk for $\mathrm{CIN}^{3}{ }^{16}$ this study revealed that age $\geq 55$ years was a risk factor for renal function impairment after second contrast exposure. This observation is in consistent with the study of Colling et $a l^{17}$ and Plurad et $a l^{28}$ both studies found a significantly increased risk of renal impairment in patients with trauma older than 55 years. It is not surprising to find that older populations are prone to developing renal injury when critically ill and undergoing invasive procedures. ${ }^{28}$ However, in contrast to most medical literature that demonstrates anaemia and hypotension as being risk factors for CIN, we did not identify the association of anaemia and hypotension with the occurrence of CIN. Since the initial low $\mathrm{Hb}$ and hypotension in patients with trauma may be transient and could be reversed after adequate resuscitation, anaemia and hypotension as risk factors may not be entirely applicable in the trauma population. ${ }^{10} 1417$ In the study by Plurad et $a l,^{28}$ analysis of 2574 trauma admissions demonstrated that initial presentation of hypotension is not an independent risk factor for posttraumatic acute renal dysfunction. It appears that the effects of hypotension on subsequent renal function are variable, depending on its duration and the patient population. Accordingly, it seems reasonable that an initial $\mathrm{SBP}<90 \mathrm{~mm} \mathrm{Hg}$ was also not identified as a risk factor for renal dysfunction following contrast exposure in our study. ${ }^{10} 14 \quad 17$ Likewise, since the initial Hb level at the acute stage cannot represent the amount of actual blood loss, an additional 24-hour Hb level of $<10 \mathrm{~g} / \mathrm{dL}$ was adopted as a variable in this study. However, we did not find an adverse impact on renal function in patients with anaemia with initial $\mathrm{Hb}<11 \mathrm{~g} / \mathrm{dL}$ or 24-hour $\mathrm{Hb}<10 \mathrm{~g} / \mathrm{dL}$. Moreover, in the groups of 
Table 3 Comparisons of the 0-hour and 48-hour SCr levels between different subgroups

\begin{tabular}{|c|c|c|c|c|}
\hline & $\begin{array}{l}\text { Angiography (-) } \\
\mathrm{n}=226(\%)\end{array}$ & & $\begin{array}{l}\text { Angiography (+) } \\
n=100(\%)\end{array}$ & \\
\hline \multicolumn{5}{|l|}{ Age $\geq 55$ years } \\
\hline 0-hour SCr & $39(17)$ & $1.18 \pm 0.43$ & $13(13)$ & $1.25 \pm 0.59$ \\
\hline 48-hour SCr & & $1.07 \pm 0.57$ & & $1.49 \pm 0.79^{\star}$ \\
\hline \multicolumn{5}{|l|}{ Gender (male) } \\
\hline 0-hour SCr & $170(75)$ & $1.10 \pm 0.31$ & $66(66)$ & $1.16 \pm 0.35$ \\
\hline 48-hour SCr & & $1.02 \pm 0.43$ & & $1.01 \pm 0.58$ \\
\hline \multicolumn{5}{|l|}{ Gender (female) } \\
\hline 0-hour SCr & $56(25)$ & $0.82 \pm 0.23$ & $34(34)$ & $0.82 \pm 0.36$ \\
\hline 48-hour SCr & & $0.70 \pm 0.20$ & & $0.83 \pm 0.56$ \\
\hline \multicolumn{5}{|l|}{ ISS $\geq 16$} \\
\hline 0-hour SCr & $126(56)$ & $1.07 \pm 0.31$ & $64(64)$ & $1.07 \pm 0.40$ \\
\hline 48-hour SCr & & $1.02 \pm 0.50$ & & $0.99 \pm 0.69^{*}$ \\
\hline \multicolumn{5}{|l|}{ SIS $4 / 5$} \\
\hline 0-hour SCr & $63(28)$ & $1.12 \pm 0.36$ & $34(34)$ & $1.09 \pm 0.48$ \\
\hline 48-hour SCr & & $1.05 \pm 0.42$ & & $0.97 \pm 0.60^{*}$ \\
\hline \multicolumn{5}{|c|}{ Large haemoperitoneum } \\
\hline 0-hour SCr & $61(37)$ & $1.08 \pm 0.33$ & $45(45)$ & $1.11 \pm 0.44$ \\
\hline 48-hour SCr & & $1.01 \pm 0.41$ & & $0.96 \pm 0.52$ \\
\hline \multicolumn{5}{|l|}{$\mathrm{SBP}<90 \mathrm{~mm} \mathrm{Hg}$} \\
\hline 0-hour SCr & $51(23)$ & $1.14 \pm 0.30$ & $28(28)$ & $1.15 \pm 0.49$ \\
\hline 48-hour SCr & & $1.06 \pm 0.51$ & & $0.98 \pm 0.63$ \\
\hline \multicolumn{5}{|c|}{ Initial $\mathrm{Hb}<11 \mathrm{~g} / \mathrm{dL}$} \\
\hline 0-hour SCr & $70(31)$ & $1.04 \pm 0.38$ & $35(35)$ & $1.07 \pm 0.43$ \\
\hline 48-hour SCr & & $0.96 \pm 0.46$ & & $1.0 \pm 0.74$ \\
\hline \multicolumn{5}{|c|}{ 24-hour $\mathrm{Hb}<10 \mathrm{~g} / \mathrm{dL}$} \\
\hline 0-hour SCr & $77(37)$ & $1.12 \pm 0.41$ & $45(45)$ & $1.01 \pm 0.39$ \\
\hline 48-hour SCr & & $1.11 \pm 0.62$ & & $1.02 \pm 0.79^{*}$ \\
\hline \multicolumn{5}{|c|}{ Initial SCr>1.5 mg/dL } \\
\hline 0-hour SCr & $23(10)$ & $1.82 \pm 0.33$ & $8(8)$ & $1.84 \pm 0.30$ \\
\hline 48-hour SCr & & $1.55 \pm 0.65$ & & $1.54 \pm 0.74$ \\
\hline \multicolumn{5}{|c|}{ Initial eGFR<60 mL/min } \\
\hline 0-hour SCr & 38 (17) & $1.50 \pm 0.38$ & $18(18)$ & $1.66 \pm 0.36$ \\
\hline 48-hour SCr & & $1.29 \pm 0.55$ & & $1.41 \pm 0.67$ \\
\hline \multicolumn{5}{|l|}{ Kidney trauma } \\
\hline 0-hour SCr & $47(21)$ & $1.14 \pm 0.27$ & $11(11)$ & $1.18 \pm 0.52$ \\
\hline 48-hour SCr & & $1.12 \pm 0.59$ & & $1.35 \pm 1.2$ \\
\hline
\end{tabular}

patients with a 24-hour $\mathrm{Hb}<10 \mathrm{~g} / \mathrm{dL}$, the patients who underwent angiography had a significant improvement, but with a very mild difference, in their 48-hour SCr level.

Although an ISS of $\geq 16$, as an indicator of major trauma, ${ }^{8} 1725$ has been reported to be independently associated with post-traumatic acute renal dysfunction, ${ }^{28}$ we did not identify an adverse impact on the renal function of those patients who had an ISS of $\geq 16$ or an SIS of $4 / 5$ and underwent angiography. This finding is in accordance with some reports describing that an elevated severity of injury does not predispose patients with trauma to an increased risk to kidney injury even after receiving contrast-enhanced imaging studies. ${ }^{10} 1314$ In patients who had an ISS of $\geq 16$ or an SIS of $4 / 5$, those who underwent angiography even had a significantly better 48-hour SCr level than those who did not. We believe that this result is most likely attributed to vigorous fluid resuscitation after the angiography. Therefore, it seems that CIN is unlikely, even after increased contrast exposure in patients with severe trauma, provided that adequate hydration is given.

While elevated SCr levels have been found to be associated with an increased risk for CIN in some studies of the trauma populations, ${ }^{3918}$ other studies reported that the initial SCr level $(\geq 1.5 \mathrm{mg} / \mathrm{dL})$ is not a risk factor for CIN. ${ }^{8} 1017$ In addition, another study reported that an SCr level of $\geq 1.3$ was not associated with CIN in patients with trauma, and suggested that the benefits may outweigh the risks for contrast administration in patients 
Table 4 Propensity score-matched patients in Greedy 1:1 matching

\begin{tabular}{|c|c|c|c|c|c|c|c|c|}
\hline & \multicolumn{2}{|c|}{ Before matching } & \multirow[b]{2}{*}{$\begin{array}{l}\text { OR } \\
(95 \% \mathrm{CI})\end{array}$} & \multirow[b]{2}{*}{ p Value } & \multicolumn{2}{|c|}{ After matching } & \multirow[b]{2}{*}{$\begin{array}{l}\text { OR } \\
(95 \% \mathrm{Cl})\end{array}$} & \multirow[b]{2}{*}{ p Value } \\
\hline & $\begin{array}{l}\text { Angiography } \\
(-) \\
n=226\end{array}$ & $\begin{array}{l}\text { Angiography } \\
(+) \\
n=100\end{array}$ & & & $\begin{array}{l}\text { Angiography } \\
(-) \\
n=91\end{array}$ & $\begin{array}{l}\text { Angiography } \\
(+) \\
n=91\end{array}$ & & \\
\hline Age & $36.5 \pm 17.7$ & $36.0 \pm 16.5$ & - & 0.824 & $35.5 \pm 15.7$ & $35.8 \pm 15.8$ & - & 0.903 \\
\hline Gender & & & & 0.086 & & & & 1.000 \\
\hline Male & $170(75.2 \%)$ & $66(66.0 \%)$ & $\begin{array}{l}0.6(0.38 \\
\text { to } 1.07)\end{array}$ & & $65(71.4 \%)$ & $65(71.4 \%)$ & $\begin{array}{l}1.0(0.53 \\
\text { to } 1.90)\end{array}$ & \\
\hline Female & $56(24.8 \%)$ & $34(34.0 \%)$ & $\begin{array}{l}1.0(0.94 \\
\text { to } 2.61)\end{array}$ & & $26(28.6 \%)$ & $26(28.6 \%)$ & $\begin{array}{l}1.0(0.53 \\
\text { to } 1.90)\end{array}$ & \\
\hline ISS & $18.1 \pm 10.9$ & $19.7 \pm 10.1$ & - & 0.226 & $20.1 \pm 10.2$ & $19.6 \pm 10.2$ & - & 0.733 \\
\hline SIS & & & & $<0.001$ & & & & 1.000 \\
\hline I & $31(13.7 \%)$ & $5(5.0 \%)$ & & & $4(4.4 \%)$ & $4(4.4 \%)$ & & \\
\hline II & $76(33.6 \%)$ & $8(8.0 \%)$ & & & $8(8.8 \%)$ & $8(8.8 \%)$ & & \\
\hline III & $56(24.8 \%)$ & $53(53.0 \%)$ & & & $48(52.7 \%)$ & $48(52.7 \%)$ & & \\
\hline IV & 39 (17.3\%) & $21(21.0 \%)$ & & & $21(23.1 \%)$ & $21(23.1 \%)$ & & \\
\hline V & $24(10.6 \%)$ & $13(13.0 \%)$ & & & $10(11.0 \%)$ & $10(11.0 \%)$ & & \\
\hline $\begin{array}{l}\text { 24-hour } \\
\mathrm{Hb}\end{array}$ & $10.8 \pm 2.3$ & $10.1 \pm 1.6$ & - & 0.002 & $10.5 \pm 1.6$ & $10.2 \pm 1.6$ & - & 0.257 \\
\hline $\begin{array}{l}\text { 0-hour } \\
\text { SCr }\end{array}$ & $1.0 \pm 0.3$ & $1.0 \pm 0.4$ & - & 0.786 & $1.0 \pm 0.3$ & $1.1 \pm 0.4$ & - & 0.338 \\
\hline $\begin{array}{l}\text { 48-hour } \\
\mathrm{SCr}\end{array}$ & $0.9 \pm 0.4$ & $1.0 \pm 0.6$ & - & 0.859 & $0.9 \pm 0.5$ & $0.9 \pm 0.5$ & - & 0.873 \\
\hline
\end{tabular}

with trauma with an elevated SCr level. ${ }^{19}$ In this study, there was no significant difference in the 48-hour SCr level between these two groups of patients when subdivided by the initial SCr level $>1.5 \mathrm{mg} / \mathrm{dL}$ or initial eGFR level $<60 \mathrm{~mL} / \mathrm{min}$. Interpretation of the results may be more complex in the trauma population because of the probable initial hypovolaemic status which is reflected in the improvement of SCr level on arrival at ED, at 48 hours, and to the time at discharge in this study. It is rational to suspect that the trauma may have caused the initial elevation in SCr level and the subsequent reduction in SCr level is most likely to be the result of restoration of fluid status rather than that of contrast administration or the procedure itself. Taken together, although controversies still exist regarding the adverse effect of pre-existing renal insufficiency on the vulnerability to CIN, it appears that extensive contrast exposure may not be contra-indicated in patients with initial elevations in the SCr level (ie, SCr $>1.5 \mathrm{mg} / \mathrm{dL}$ ). Accordingly, the results of this study support the viewpoint of previous studies that mild or moderate renal insufficiency should not preclude patients from receiving contrastenhanced imaging studies or therapeutic procedures, because the benefits outweigh the risk of missing a possible injury or delaying appropriate manage-

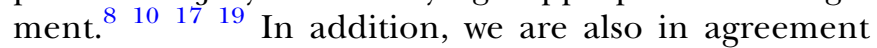
with the study of Katzberg et $a l,{ }^{11}$ which reported that thresholds of SCr above which contrast medium were withheld for enhancement image studies should be increased to improve the accuracy of enhancement imaging studies.
This study has its limitations. First is the retrospective design with its inherent bias and relatively small numbers of patients included in this study. In addition, there was a majority of young population with relative few old patients in our study. A prospective larger randomised controlled trial would provide more validated information regarding the findings in this study. Second, instead of creatinine clearance, which is able to reflect a more accurate renal function, SCr level was used for comparison under the condition that 24-hour urine collection was not possible in the ED. Finally, the lack of detailed data on administrated fluid volume, contrast dosage and long-term renal function after discharge may cause some bias; however, we expect that these biases were randomly existent in both groups of patients.

\section{CONCLUSIONS}

This study demonstrated that angiography did not increase the incidence of CIN and did not have an adverse effect on renal function in patients with BSI who had undergone CECT. These findings support the NOM of patients with BSI provided that close monitoring is done to ensure that further contrast exposure from angiography does not impair renal function, even under the setting of anaemia, hypotension or severe trauma.

\section{Author affiliations}

${ }^{1}$ Division of Trauma, Department of Surgery, Kaohsiung Chang Gung Memorial Hospital and Chang Gung University College of Medicine,

Kaohsiung, Taiwan 
${ }^{2}$ Division of Cardiology, Department of Internal Medicine, Kaohsiung Chang Gung Memorial Hospital and Chang Gung University College of Medicine, Kaohsiung, Taiwan

${ }^{3}$ Division of General Surgery, Department of Surgery, Kaohsiung Chang Gung Memorial Hospital and Chang Gung University College of Medicine, Kaohsiung, Taiwan

Contributors T-MH was responsible for the literature search, study design, data collection and drafting of the manuscript. T-HT participated in the design of the study and performed the statistical analysis. C-CL designed the study and revised the final version of the manuscript. C-HH was responsible for the writing of the manuscript. All authors read and approved the final manuscript. All authors fulfil the authorship criteria given by the International Committee of Medical Journal Editors (ICMJE).

Funding This research was supported by a grant from Kaohsiung Chang Gung Memorial Hospital and Chang Gung University College of Medicine (CMRPG8E1271).

Competing interests None declared.

Ethics approval The Chang Gung Medical Foundation Institutional Review Board (IRB) approved this study prior to proceeding with it (approval number 102-4441B)

Provenance and peer review Not commissioned; externally peer reviewed.

Data sharing statement No additional data are available.

Open Access This is an Open Access article distributed in accordance with the Creative Commons Attribution Non Commercial (CC BY-NC 4.0) license, which permits others to distribute, remix, adapt, build upon this work noncommercially, and license their derivative works on different terms, provided the original work is properly cited and the use is non-commercial. See: http:// creativecommons.org/licenses/by-nc/4.0/

\section{REFERENCES}

1. Ikegami $Y$, Suzuki T, Nemoto $C$, et al. Establishment and implementation of an effective rule for the interpretation of computed tomography scans by emergency physicians in blunt trauma. World J Emerg Surg 2014;9:40.

2. Hsieh TM, Cheng Tsai T, Liang JL, et al. Non-operative management attempted for selective high grade blunt hepatosplenic trauma is a feasible strategy. World J Emerg Surg 2014:9:51.

3. van der Vlies $\mathrm{CH}$, Saltzherr TP, Reekers JA, et al. Failure rate and complications of angiography and embolization for abdominal and pelvic trauma. J Trauma Acute Care Surg 2012;73:1208-12.

4. Liu PP, Lee WC, Cheng YF, et al. Use of splenic artery embolization as an adjunct to nonsurgical management of blunt splenic injury. J Trauma 2004;56:768-72; discussion 73.

5. Mehran R, Nikolsky E. Contrast-induced nephropathy: definition, epidemiology, and patients at risk. Kidney Int Suppl 2006(100):S11-15.

6. Stacul F, van der Molen AJ, Reimer P, et al. Contrast induced nephropathy: updated ESUR Contrast Media Safety Committee guidelines. Eur Radiol 2011;21:2527-41.

7. Beckett KR, Moriarity AK, Langer JM. Safe use of contrast media: what the radiologist needs to know. Radiographics 2015;35:1738-50.

8. Matsushima K, Peng M, Schaefer EW, et al. Posttraumatic contrast-induced acute kidney injury: minimal consequences or significant threat? J Trauma 2011;70:415-19; discussion 19-20.
9. Kulvatunyou N, Rhee PM, Carter SN, et al. Defining incidence and outcome of contrast-induced nephropathy among trauma: is it overhyped? Am Surg 2011;77:686-9.

10. Vassiliu P, Sava J, Toutouzas KG, et al. Is contrast as bad as we think? Renal function after angiographic embolization of injured patients. J Am Coll Surg 2002;194:142-6.

11. Katzberg RW, Newhouse $\mathrm{JH}$. Intravenous contrast medium-induced nephrotoxicity: is the medical risk really as great as we have come to believe? Radiology 2010;256:21-8.

12. McDonald RJ, McDonald JS, Carter RE, et al. Intravenous contrast material exposure is not an independent risk factor for dialysis or mortality. Radiology 2014;273:714-25.

13. Eriksson $\mathrm{M}$, Brattström $\mathrm{O}$, Mårtensson $\mathrm{J}$, et al. Acute kidney injury following severe trauma: risk factors and long-term outcome. J Trauma Acute Care Surg 2015;79:407-12.

14. Kim DY, Kobayashi L, Costantini TW, et al. Is contrast exposure safe among the highest risk trauma patients? J Trauma Acute Care Surg 2012;72:61-6; discussion 66-7.

15. Liu KD, Brakeman PR. Renal repair and recovery. Crit Care Med 2008;36(4 Suppl):S187-92.

16. McGillicuddy EA, Schuster KM, Kaplan LJ, et al. Contrast-induced nephropathy in elderly trauma patients. J Trauma 2010;68:294-7.

17. Colling KP, Irwin ED, Byrnes MC, et al. Computed tomography scans with intravenous contrast: low incidence of contrast-induced nephropathy in blunt trauma patients. J Trauma Acute Care Surg 2014;77:226-30.

18. Hipp A, Desai S, Lopez C, et al. The incidence of contrast-induced nephropathy in trauma patients. Eur J Emerg Med 2008; 15:134-9.

19. Tremblay LN, Tien $\mathrm{H}$, Hamilton $\mathrm{P}$, et al. Risk and benefit of intravenous contrast in trauma patients with an elevated serum creatinine. J Trauma 2005;59:1162-6; discussion 66-7.

20. Moore EE, Cogbill TH, Jurkovich GJ, et al. Organ injury scaling: spleen and liver (1994 revision). J Trauma 1995;38:323-4.

21. Levey AS, Bosch JP, Lewis JB, et al. A more accurate method to estimate glomerular filtration rate from serum creatinine: a new prediction equation. Modification of Diet in Renal Disease Study Group. Ann Intern Med 1999;130:461-70.

22. Parfrey PS, Griffiths SM, Barrett BJ, et al. Contrast material-induced renal failure in patients with diabetes mellitus, renal insufficiency, or both. A prospective controlled study. N Engl J Med 1989; 320:143-9.

23. Mehta RL, Kellum JA, Shah SV, et al. Acute Kidney Injury Network: report of an initiative to improve outcomes in acute kidney injury. Crit Care 2007;11:R31.

24. Bellomo R, Ronco C, Kellum JA, et al. Acute renal failuredefinition, outcome measures, animal models, fluid therapy and information technology needs: the Second International Consensus Conference of the Acute Dialysis Quality Initiative (ADQI) Group. Crit Care 2004;8:R204-12.

25. Shashaty MG, Meyer NJ, Localio AR, et al. African American race, obesity, and blood product transfusion are risk factors for acute kidney injury in critically ill trauma patients. J Crit Care 2012;27:496-504

26. Callcut RA, Johannigman JA, Kadon KS, et al. All massive transfusion criteria are not created equal: defining the predictive value of individual transfusion triggers to better determine who benefits from blood. J Trauma 2011;70:794-801.

27. Guth MC, Kaufner L, Kleber C, et al. [Therapy of trauma-induced coagulopathy-what is the evidence?]. Anasthesiol Intensivmed Notfallmed Schmerzther 2012;47:528-39; quiz 40.

28. Plurad D, Brown C, Chan L, et al. Emergency department hypotension is not an independent risk factor for post-traumatic acute renal dysfunction. J Trauma 2006;61:1120-7. discussion 27-8. 